\title{
Segmental Phonology of Bilingual Nigerian Adult Wernicke's Aphasics
}

\author{
Adesina Bukunmi Sunday ${ }^{1, *}$ \\ ${ }^{1}$ Department of English, University of Ibadan, Ibadan, Nigeria \\ * Correspondence: Department of English, University of Ibadan, Ibadan, Nigeria $\quad$ E-mail: sinadaybuk@yahoo.com
}

Received: November 29, 2012

Accepted: December 24, $2012 \quad$ Online Published: February 20, 2013

doi:10.5430/wjel.v3n1p50

URL: http://dx.doi.org/10.5430/wjel.v3n1p50

\begin{abstract}
Research on the phonology of aphasia has been mainly on the language of aphasics who are first language speakers. Only few studies on Nigerian aphasics have been concerned with linguistic analysis. This situation is quite unhealthy for the treatment and rehabilitation of Nigerian aphasics. Therefore, this paper examined the segmental phonology of bilingual Nigerian Wernicke's aphasics to provide explanation for the noticeable patterns of their phonology. Ten bilingual Nigerian adult Wernicke's aphasics from a Nigerian teaching hospital were purposively sampled. They were both in-patients and out-patients. Their speeches were tape-recorded. The data were subjected to perceptual analysis, complemented with frequency count and simple percentage. Three major forms of deviation were identified at the segmental level of the speech of the subjects: deletion, substitution, and epenthesis, with deletion being the most prominent, followed by substitution. The deviation identified affected consonants more than vowels. The brain damage affected plosives and alveolars more than any other class of sound. There was no consistent pattern of the way the deviation forms affected vowels. Optimality Theory was used to explicate the way constraints were ranked by the subjects. Generally, the subjects ranked markedness above faithfulness.
\end{abstract}

Keywords: Nigerian Wernicke's aphasics; constraints; rehabilitation; segmental phonology; bilingual

\section{Introduction}

Despite the fact that both theoretical and practical advances have been made in the study of aphasia, there are only few works on the phonology of bilingual Nigerian aphasics. What exist mainly are works on first language aphasics (such as Bouhman and Grumbaum, 1925; Goldstein, 1948; Luria 1966; Jakobson, 1968, 1971; Lecours and Lhermitte 1969; Green 1969; Goodglass et al., 1972; Zurif et al. 1972; Blumstein 1973; Caramazza and Zurif 1976; Peuser and Fittschen, 1977; Goodglass and Kaplan,1983; Niemi, et al. 1985. Not only this, there is virtually no attention devoted to the language of Nigerian aphasics (Congress on Child Language and Communication Disorders, 2006). This has limited their care and rehabilitation to only the medical personnel. This is seriously affecting the rate of recovery of the lost language abilities of Nigerian aphasics. In fact, only few of them come to clinics after being discharged, because the needed speech therapy is not available. There cannot be any meaningful language therapy without any systematic description of the language of Nigerian aphasics generally.

A notable research work on the language Nigerian aphasics is Salami (2005), who used a 58-year old stroke patient as a case study. The woman had been hypertensive for 22 years. The speech of Linda (the patient's pseudonym) was characterized by omission, such as 'range' for orange. Her speech was also characterized by substitution, such as 'beat' for meat. She equally added phonemes, as seen in 'ealse' for ease. Besides, she distorted some words, for example, 'dest' for diet. According to Salami, in the area of speech comprehension, Linda was unable to link an ongoing conversation or utterance with what had gone before. She had to be reminded about an earlier topic before she understood what was meant.

A noticeable weakness in Salami's work is that he does not situate his analysis within any phonological theory. He only identifies some of the phonemes substituted, added or distorted. He does not account for the phonological processes involved. He does not also go beyond the claims of earlier scholars, such as Goodglass and Kaplan (1983) and Blumstein (1988).

Sunday (2010) concentrates on the suprasegmental features of bilingual Nigerian adult aphasics. He sampled 20 aphasics and used Optimality Theory to account for the patterns noticed in their language. He found that the stress and 
intonational patterns of the subjects were not affected by aphasia, but the rhythm of their speeches was affected. He then proposed Syllable-Pause Timing to account for the rhythm of their speech, since none of the existing theories of rhythm adequately accounts for it.

In view of the current state of research on Nigerian aphasics, this paper investigated the segmental phonology of bilingual Nigerian adult Wernicke's aphasics, from the perspective of Optimality Theory (OT). This was with a view to making some generalizations to help in the treatment of aphasics, particularly those with Wernicke's aphasia, and explaining the way they rank constraints.

\section{Types of Aphasia}

There are seven main types of aphasia, namely: Broca's, Wernicke's, Global Aphasia, Conduction Aphasia. Transcortical Motor Aphasia. Transcortical Sensory Aphasia, and Mixed Transcortical Aphasia. (Whitaker, 1975:38-39; Crystal, 1987:271; Wingfield, 1992; Wertz, 1996:48; Edwards, 2002:20; Caplan, 2003:585).

Broca's aphasia is also known as motor or expressive aphasia. The lesion is located in the lower frontal lobe, just anterior to the Rolandic fissure, which divides the frontal and parietal lobes. In it, there is non-fluent and effortful speech articulation; substitution; simplification of consonant clusters; and missing of function words and bound morphemes. Broca's aphasics know what to say but they lack the means with which to properly present their ideas (Caplan, 2003:585; Dickey et al., 2007:2; Thompson and Shapiro, 2005: 1021; Dickey and Thompson, 2009: 563; Thompson and Choy, 2009; Choy and Thompson, 2010: 551; Thompson et al., 2010 1243).

Wernicke's aphasia is otherwise known as sensory aphasia or receptive aphasia; this is because this aphasia affects linguistic comprehension mainly. The lesion is located in the upper surface of the temporal lobe, affecting the auditory cortex and, sometimes, the parietal lobe. It is characterized by fluent spontaneous speech; phonemic paraphasias; verbal paraphasias; paragrammatisms; neologisms, use of general proforms and hackneyed phrases; problems with comprehending the speech of others; problems in retrieving words from memory; and circumlocutions (Parker, 1986: 191; Crystal 1987: 271; Dickey and Thompson, 2004:111).

Global aphasia occurs when there is multiple damage to the language area of the brain. In conduction/ associative aphasia, the lesion affects the arcuate fasciculus, the association fibres that connect Broca's area. In it, the speech is fluent but there is intermittent correction, repetition and omission of words. There is word retrieval problem although the individual understands spoken language (Parker, 1986:208). Transcortical aphasia results from damage to the language areas of the left hemisphere beyond the main language areas. There are three main types of this aphasia. The first one is transcortical motor aphasia. This is like Broca's aphasia, but the individual retains the ability to repeat words, phrases and sentences. The second is transcortical sensory aphasia. This is similar to Wernicke's aphasia, but there is ability to retain and repeat what is said. The third type is mixed transcortical aphasia, which is like global aphasia. It is also called isolation syndrome. There is problem of interpretation and comprehension; spontaneous speech is also affected, though repetition is preserved to some extent (Edwards, 2002:20; Sunday, 2008; Cho and Thompson, 2010).

\section{The Data}

The data for the study were got from the tape-recorded speech of ten purposively sampled bilingual Nigerian adult Wernicke's aphasics. They were both in-patient and out-patients at the University College Hospital, Ibadan, Nigeria. The subjects were stroke patients who had Wernicke's aphasia and were not less than 35 years old.

The unstructured interview technique was used to elicit information from the subjects. They were asked to narrate the onset of the stroke that led to their aphasic condition. Some issues relating to their feelings about their loss of speech were also raised in the course of interacting with them.

The consultant neurologists on duty did the clinical diagnosis of the patients. Some other useful pieces of information, such as demographic and relevant clinical data, were got from their case files. But the subjects were identified as P1, P2, and P3 and so on, so as to hide their identities. A normative text, made up of a short passage containing some words representing some of the concepts examined in the study, was also administered to the subjects.

The data were analyzed using the perceptual approach. The recorded data were listened to several times so as to discover the segmental features being investigated. The analysis employed principally an endonormative approach, assessing the segmental phonology of the subjects based on Nigerian English (NE) rather than Received Pronunciation (RP). The statistical approach was also used to make some generalizations. The instances of deviation noticed in their 
speech were identified. The frequency of occurrence of each of these instances of deviation was recorded. Thereafter, the frequencies and percentages of occurrence of the forms of deviation were compared. Optimality Theory (OT) was used to account for how some of these instances of deviation emerged as optimal outputs for the subjects.

\section{Optimality Theory (OT)}

Optimality Theory (OT) is based on the assumption that Universal Grammar (UG) is made of a set of violable constraints (Oyebade, 1998; Fox, 2002:198). These constraints, that is, statements that spell out universal properties of language, are ranked in different ways in each language. It is these differences between constraints rankings that produce different patterns which results in systematic variations among languages (Archangeli, 1997:11).

GEN (Generator) and EVAL (Evaluator) mediate between the input and the output. GEN creates linguistic objects and notes their faithfulness to the input under consideration. EVAL uses the constraint hierarchy of the language to select the best candidate(s) for a given input among the candidates produced by GEN. The way a language ranks the universal set, known as $\mathrm{CON}$, is the constraint hierarchy for that language. The foregoing explanation is presented in the schema below:

$$
\text { Input } \rightarrow \mathrm{GEN} \rightarrow \text { candidate } \rightarrow \mathrm{EVAL} \rightarrow \text { Output }
$$

Adapted from (McCarthy, 2002:10)

The main assumption in OT is that the grammar of a particular language is a specific way, out of many possible ways, to rank a set of universal and violable constraints. This implies that, by rearranging the basic universal material (that is reranking the constraints) of one language, we can build another grammar (Kager, 1999: 34; Cartell, 2006:194).

OT identifies two basic constraint types: faithfulness and markedness. The latter requires identity between the input and the output; it uses the nature of the disparity between the input and the output which GEN supplies. Initially, Prince and Smolensky (1993) proposed the notion of containment, which requires that the input be contained in each of the output candidates. However, this has given way to McCarthy and Prince's (1995) Correspondence Theory. While the Containment Theory views epenthesis as an instance of overparsing phonetic interpretations of empty positions and deletion as an instance of underparsing, the Correspondence Theory predicts that the segments involved in epenthesis may participate in phonological processes and that the two processes show the dominance of syllabic well-formedness over faithfulness (Kager, 1999 100). That is, the two phonological processes show that faithfulness is violated at the instance of well-formedness.

The Correspondence Theory of faithfulness posits that there is a correspondence $\mathrm{K}$ from the input to each of its output candidates (McCarthy, 2002:12). For example, any epenthetic vowel does not correspond to the input, whereas other segments do. In such a case, the constraint DEP is violated. This constraint says that K must be surjective (onto), so that every element of the output is in correspondence with the output; that is, the output depends upon the input. Similarly, a deleted segment violates the constraint MAX, which requires that the inverse relation $\mathrm{K}^{-1}$ be surjective (onto), so that every element of the input is in correspondence with the output; that is, the input is maximally expressed in the output (McCarthy and Prince, 1995).

Markedness constraints evaluate the form of the output candidate favouring a particular structure over others without making reference to the input (Moreton, 1996/1999). For instance, it could favour syllables with coda over syllables without coda. Any constraint which assigns violation marks to a candidate based mainly on its output structure, not considering its similarity to the input, is referred to as markedness constraint. If a candidate is marked by or with respect to that constraint, such a candidate receives at least one violation-mark from it (McCarthy, 2002:14).

\section{The Analysis}

\subsection{Background Information about Each Subject}

The female subjects were 4 , while the males were 6 . All of them were right handed and the stroke affected the right side of all of them. 5 of them had left hemispheric cerebro-vascular disease (CVD); the same number had right hemispheric CVD.

\subsection{Segmental Phonology of Bilingual Nigerian Adult Wernicke's Aphasics}

Table 1 below shows the frequencies of occurrence and the percentages of the forms of deviation identified in the speech of each of the Wernicke's aphasics. These were seen as deviation and not errors. When learners commit errors, they are still in full control of their senses; that is, their language areas are still intact. They commit these errors as a 
result of faulty learning, mother-tongue interference and other environmental factors. But the peculiarities noticeable in the speech of these aphasics were not due to faulty learning, mother-tongue interference or environmental factors. Rather, they were a result of damage to their brains. This damage engendered re-organization and disorganization of the language faculties of these people. In fact, some of them think they are communicating even when their speech is incomprehensible to a non-aphasic adult.

Table 1: Major Forms of Deviation in the Speech of the Wernicke's Aphasics

\begin{tabular}{|c|c|c|c|c|c|c|c|c|c|c|c|c|c|c|c|c|c|c|c|c|c|c|}
\hline \multirow[t]{2}{*}{ DEVIATION } & & & \multicolumn{2}{|l|}{ P1 } & \multicolumn{2}{|l|}{$\mathrm{P} 2$} & \multicolumn{2}{|l|}{ P3 } & \multicolumn{2}{|l|}{ P4 } & \multicolumn{2}{|l|}{ P5 } & \multicolumn{2}{|l|}{ P6 } & \multicolumn{2}{|c|}{ P7 } & \multicolumn{2}{|l|}{ P8 } & \multicolumn{2}{|l|}{ P9 } & \multicolumn{2}{|c|}{ P10 } \\
\hline & & & $f$ & $\%$ & $\mathrm{f}$ & $\%$ & $f$ & $\%$ & $f$ & $\%$ & $f$ & $\%$ & $f$ & $\%$ & $\mathrm{f}$ & $\%$ & $f$ & $\%$ & $f$ & $\%$ & $f$ & $\%$ \\
\hline \multirow[t]{6}{*}{ DELETION } & Vowel & In & 1 & & - & & - & & - & & - & & 1 & & - & & - & & - & & - & \\
\hline & & Med & 1 & 11.1 & 1 & 8.3 & - & 3.0 & 1 & 9.1 & - & & - & 10 & - & & - & & - & & - & 7.1 \\
\hline & & Fin & - & & - & & 1 & & - & & - & & - & & - & & - & & - & & 1 & \\
\hline & Consonant & In & - & & 2 & & 4 & & 1 & & 2 & & 1 & & 3 & & - & & 1 & & - & \\
\hline & & Med & 7 & 50 & 2 & $33 . .3$ & 2 & 36.4 & - & 18.2 & - & $33 . .3$ & - & 30 & - & 44.4 & 1 & 40 & 1 & 33.3 & - & 71.4 \\
\hline & & Fin & 2 & & - & & 6 & & 1 & & 1 & & 2 & & 1 & & 3 & & 1 & & 10 & \\
\hline \multirow[t]{6}{*}{ SUBSTITUTION } & Vowel & In & - & & - & & - & & 1 & & 2 & & - & & 3 & & - & & 1 & & 2 & \\
\hline & & Med & - & & - & & 2 & 6.1 & 1 & 18.2 & 1 & $33 . .3$ & - & & - & 33.3 & - & & 1 & 22.2 & - & \\
\hline & & Fin & - & & - & & - & & - & & - & & - & & - & & - & & - & & - & \\
\hline & Consonant & In & - & & 1 & & - & & 5 & & - & & 4 & 40 & - & & 2 & & 3 & & - & \\
\hline & & Med & 3 & 16.7 & 1 & 33.3 & - & 3.0 & - & 45.3 & - & & - & & 1 & 22.2 & 1 & 30 & 1 & 44.4 & 1 & 7.1 \\
\hline & & Fin & - & & 2 & & 1 & & - & & - & & - & & 1 & & - & & - & & - & \\
\hline \multirow[t]{6}{*}{ EPENTHESIS } & Vowel & In & 1 & & - & & - & & - & & 1 & & - & & - & & - & & - & & - & \\
\hline & & Med & 2 & 16.7 & 1 & 8.3 & - & 9.1 & - & & - & $33 . .3$ & 2 & 20 & - & & - & & - & & - & \\
\hline & & Fin & - & & - & & 3 & & - & & 2 & & - & & - & & - & & - & & - & \\
\hline & Consonant & In & 1 & & - & & - & & - & & - & & - & & - & & 3 & & - & & - & \\
\hline & & Med & - & 5.6 & 1 & 16.7 & 3 & 42.4 & 1 & 9.1 & - & & - & & - & & - & 30 & - & & - & \\
\hline & & Fin & - & & 1 & & 11 & & - & & - & & - & & - & & - & & - & & - & \\
\hline Total & & & 18 & 100 & 12 & 100 & 33 & 100 & 11 & 100 & 9 & 100 & 10 & 100 & 9 & 100 & 10 & 100 & 9 & 100 & 14 & 100 \\
\hline
\end{tabular}

As shown in this table, P3 has the highest instances of deviation (33). Incidentally, P3 was the youngest among the subjects.

A general view of the forms of deviation in all the subjects under analysis is presented in Table 2 below:

Table 2: Summary of the Phonological Processes in the Wernicke's Aphasics

\begin{tabular}{|c|c|c|c|c|c|c|c|c|c|c|c|c|c|c|c|c|c|c|c|c|c|}
\hline & \multicolumn{21}{|c|}{ DEVIATION } \\
\hline & \multicolumn{7}{|c|}{ Deletion } & \multicolumn{7}{|c|}{ Substitution } & \multicolumn{7}{|c|}{ Epenthesis } \\
\hline & \multicolumn{3}{|c|}{ Vowel } & \multicolumn{4}{|c|}{ Consonant } & \multicolumn{3}{|c|}{ Vowel } & \multicolumn{4}{|c|}{ Consonant } & \multicolumn{3}{|c|}{ Vowel } & \multicolumn{4}{|c|}{ Consonant } \\
\hline & In & Med & Fin & In & Med & Fin & Total & In & Med & Fin & In & Med & Fin & Total & In & Med & Fin & In & Med & Fin & Total \\
\hline $\mathrm{F}$ & 2 & 3 & 2 & 14 & 13 & 27 & 61 & 9 & 5 & - & 15 & 8 & 4 & 41 & 2 & 5 & 5 & 4 & 5 & 12 & 33 \\
\hline$\%$ & 2.9 & 4.4 & 2.9 & 22.1 & 22.1 & 45.6 & 100 & 21.3 & 12.8 & - & 36.2 & 17.0 & 12.8 & 100 & 4.3 & 15.4 & 18.0 & 10.3 & 15.4 & 35.9 & 100 \\
\hline
\end{tabular}

As revealed in this table, deletion has the highest frequency of occurrence (61). 2 instances of deletion involved vowels in word-initial position; 3 involved vowels in word-medial position; while 2 involved vowels in word-final position. 14 of the instances of consonant deletion were in word-initial position; 13 were also in word-medial position; while 27 were in word-final position. Vowel substitution occurred only in word-initial and word-medial positions. 9 out of the 14 instances of vowel substitution involved vowels in word-initial position; the remaining 5 instances took place in word-medial position. 15 out of the 27 instances of consonant substitution occurred in word-initial position; 8 occurred 
in word-medial position; while 4 occurred in word-final position. Altogether, 41 instances of substitution of segment were recorded. 2 of the instances of vowel epenthesis occurred in word-initial position; 5 at word-medial position; and 5 in word-final position. 4 of the cases of consonant epenthesis occurred in word-initial position; 5 in word-medial position; and 12 in word-final position. In all, there were 33 instances of epenthesis of segments.

The foregoing analysis reveals that deletion accounts for $45.2 \%$ of the deviation in the speech of the Wernicke's aphasics. Substitution accounts for $30.4 \%$ of the deviation in their speech. Epenthesis accounts for the remaining 24.4\%. Table 3 below captures this.

Table 3: Summary of the Forms of Deviation in the Wernicke's Aphasics

\begin{tabular}{lll}
\hline DEVIATION & $\mathrm{F}$ & $\%$ \\
\hline DELETION & 61 & 45.2 \\
SUBSTITUTION & 41 & 30.4 \\
EPENTHESIS & 33 & 24.4 \\
TOTAL & 135 & 100 \\
\hline
\end{tabular}

Deletion and substitution affected consonants more than vowels. This indicates that vowel production is easier for these subjects than consonant production is. In fact, no vowel substitution was recorded in word-final position. The relative ease of vowel production is, perhaps, responsible for the high frequency of vowel epenthesis. In some cases where the production of consonant clusters was difficult, the subjects under consideration resorted to simplification of these consonant clusters through vowel insertion.

Consonant deletion was more prominent in word-final position than the other two word positions; but consonant substitution was more frequent in word-initial position than the other two word positions. This suggests that the initiation of speech production in these subjects was not as difficult as it is in Broca's aphasia. Consonant epenthesis was more pronounced at word-final position than the other two word positions. This was so because $\mathrm{P} 4 \mathrm{added} / \mathrm{n} /$ to almost all words. Some of the words did not have a nasal consonant before or after them. The stroke he had disfigured his mouth, making him to nasalize almost every word. The three word positions were relatively equally affected by deletion. It was in consonants that deletion had great effects. Out of the 61 instances of deletion identified, 54 (88.5\%) involved consonants. Word-final consonants were the most affected; 27 out of the 54 instances of consonant deletion $(50.0 \%)$ occurred in word-final position. The other two word positions were equally affected. This pattern suggests that the initiating stage of word articulation is relatively easier than its completion in Wernicke's aphasia.

By nature, the speech of Broca's aphasics is more effortful than that of Wernicke's aphasics. It seems that the long process of word retrieval associated with Wernicke's aphasia (Crystal, 1987:271) contributes to the difficulty in initiating speech production in this aphasia. This could account for the deletion of consonants. The high occurrence of consonant deletion in word-final position could be attributed to the fact that the neural pathway gets weakened before the completion of articulation. Consonants are more affected than vowels because there are strictures in the production of the former, whereas there is no stricture in the production of the latter.

\subsection{The Phonological Processes in the Speech of the Subjects}

The three phonological processes discovered are discussed below.

\subsubsection{Deletion}

The vowel most affected by deletion was $/ \mathrm{N}$. This is a weak vowel often found in unstressed syllable in English. This accounts for its being more frequently affected by deletion. Many consonants were affected by deletion. Table 4 below shows the consonants affected.

Table 4: Consonants Deleted by the Wernicke's Aphasics

\begin{tabular}{llll}
\hline \multicolumn{1}{l}{ Consonants } & F & $\%$ \\
\hline$/ \mathrm{d} /$ & & 11 & \\
$/ \mathrm{t} /$ & Plosives & 10 & \\
$/ \mathrm{k} /$ & & 6 & 51.9 \\
$\mathrm{~h} / \mathrm{b}$ & 1 & \\
& & & \\
/s/ & & & \\
\hline
\end{tabular}




\begin{tabular}{llll}
\hline$/ \mathrm{r} /$ & Fricatives & 4 & 24.1 \\
$/ \mathrm{h} /$ & & 1 & \\
& & 5 & 11.1 \\
$/ \mathrm{w} /$ & & \\
$/ \mathrm{j} /$ & Semi-vowels & 1 & \\
& & 3 & \\
$/ \mathrm{n} /$ & & 1 & 9.3 \\
$/ \mathrm{m} /$ & Nasals & 1 & \\
$/ \mathrm{n} /$ & & & \\
& & 2 & 3.7 \\
\hline $\mathrm{l} /$ & lateral & 54 & 100 \\
\hline Total & & 54
\end{tabular}

As shown in this table, plosives top the list of deleted consonants, accounting for $51.9 \%$ of the cases of deletion; fricatives follow with 24.1\%; semi-vowels have $11.1 \%$; nasals $9.3 \%$; and lateral $3.7 \%$. The high incidence of the deletion of plosives is due to their manner of articulation, which has strictures more difficult than other strictures. This table also shows that alveolar sounds were the most often deleted consonants. The alveolar sounds deleted were: /d/ (11), /t/ (10), /s/ (8), /r/ (4), n (3), and /1/ (2). They all form 38 instances out of the 54 instances of deletion analyzed $(70.3 \%)$. A reason for this is that the articulation of alveolar sounds involves the tip or the blade of the tongue touching the alveolar ridge. This movement appears more difficult than other kinds of articulatory movements for the aphasics.

\subsubsection{Substitution}

Substitution follows deletion in prominence in the Wernicke's aphasics. No instance of vowel substitution was recorded in word-final position. In word-initial position, there were 9 instances of vowel substitution. In word-medial position, there were 5 instances of vowel substitution. Substitution of vowels was more common than deletion of vowels in the speech of the subjects. The difficulty in speech initiation could be responsible for the high occurrence of vowel substitution in word-initial position. Rather than delete the vowels outright, the subjects substituted other vowels closely related to the ones in the input. This trend continued till the middle of the word; but it stopped there. Substitution of consonants was more pronounced at the word-initial position than the other two word positions. 15 out of the 27 instances of consonant substitution (55.6\%) occurred in this position. The difficulty associated with the initiation of word production in these subjects is a likely reason for this substitution. Although the words were not produced in isolation, there were pauses which made the production of each word begin almost afresh. Since consonant deletion occurred more at word-final position, consonant substitution was not all that prominent in this position; this position had the lowest instances of consonant substitution -4 out of $27(14.8 \%)$.

Three vowels featured prominently as substitutes for /I// / / occurred 5 times; / $/ \mathcal{E} /$ and /ui/ occurred 3 times each. The other instances of vowel substitution affected /OI,ə, e/. Substitution of consonants did not show consistency. However, /s/ was more consistently substituted as /t/ than any other consonant. At times too, /p/ and /f/ were used interchangeably. A notable feature of substitution in the data is that the consonants substituted for each other shared either the same place or manner of articulation. But, in some cases, the places and manners of articulation were slightly different, for instance, $/ \mathrm{f} /$ and $/ \mathrm{p} /$ : while $/ \mathrm{f} /$ is voiceless labio-dental fricative, $/ \mathrm{p} /$ is voiceless bilabial plosive.

\subsubsection{Epenthesis}

Epenthesis had the least frequency of occurrence in the speech of these subjects. Vowels in word-medial and word-final positions were more affected than vowels in word-initial position. The three word positions recorded 2, 4, and 5 instances of vowel epenthesis, respectively. Vowel epenthesis serves as a way of reducing the difficulty associated with consonant clusters which is common in English. Most of the cases of vowel epenthesis recorded here affected those words that have consonant clusters in the middle. The cases of vowel epenthesis in word-final position often involved words that end only with syllabic consonants. The subjects often inserted a vowel to ease the production of the last consonant. The most often inserted vowel was $/ \mathrm{i} / / \mathrm{e} /$ and $/ \mathrm{u} /$ occurred at times too.

Epenthesis of consonants featured more prominently in word-final position than the other word positions, having 12 out of the 21 cases analyzed (57.0\%). The most frequently inserted consonant was $/ \mathrm{n} /$. Out of the 21 cases of consonant epenthesis, it occurred 14 times (66.7\%). Most of the subjects that inserted this consonant had disfigured mouths. Other 
consonants inserted were $/ \mathrm{h}, 1, \mathrm{j}, \mathrm{p}, \mathrm{k}, \mathrm{s}, \mathrm{S} /$.

5.4 Constraints Ranking by the Subjects

Before examining the way constraints are ranked by the Wernicke's aphasics, some examples of the forms of deviation in the speech of the Wernicke's aphasics are presented:

\section{Deletion}

\begin{tabular}{|c|c|c|c|c|}
\hline & & & NE & RP \\
\hline 1. Poblem & [proble] & for problem & /problem/ & /problem/ \\
\hline 2. Hypertenion & [hæpætenæn] & for hypertension & /halpæten]pn/ & /halpətenfn/ \\
\hline 3.Prou & [prao] & for proud & /praod/ & /pravd/ \\
\hline 4. Caendar & [kæendæ] & for calendar & /kælendæ/ & /kælində \\
\hline 5. Milely & 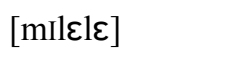 & for immediately & /ImIdIEtle/ & /ImIdiətli/ \\
\hline 6. Esday & [esd $\varepsilon]$ & for yesterday & /jestædع/ & /jestədi/ \\
\hline 7. Aise & {$[\varepsilon s]$} & for raise & /rعs/ & /reIs/ \\
\hline 8. Ank & [ænk] & for thank & /tænk/ & /Өæりk/ \\
\hline 9. Bea & [bea] & for better & /beta/ & /betə/ \\
\hline 10. Respoded & [resppded] & for responded & /respDnded/ & /rIspDndId/ \\
\hline
\end{tabular}

\section{Substitution}

\begin{tabular}{|c|c|c|c|c|}
\hline & & & NE & RP \\
\hline 1. Fap & [fæp] & for pap & /pæp/ & $/ \mathrm{pæp} /$ \\
\hline 2. Quckly & {$[\mathrm{k} \mho \mathrm{kl} l \varepsilon]$} & for quickly & /kUIklع/ & /kwIkli/ \\
\hline 3. Englit & [Inglit] & for English & /InglIJ/ & /Inglif/ \\
\hline 4. Kawor & [kæwD/ & for carrot & /kærDt/ & /kærət/ \\
\hline 5. Teach & [ti:t] & for which & /wi:ts/ & /wi:t5/ \\
\hline 6. Toing & [toin] & for going & /goin/ & /gəひIy/ \\
\hline 7. Kilo & [kailo] & for biro & /bairo/ & /baIrəひ/ \\
\hline 8. Festerday & [festad $\varepsilon]$ & for yesterday & /jestade/ & /jestədi/ \\
\hline 9. Pully & 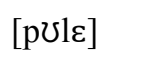 & for fully & /fulع/ & /fษlil/ \\
\hline 10. Polit & [polit] & for police & /polis/ & /pəli:s/ \\
\hline
\end{tabular}

\section{Epenthesis}

\begin{tabular}{|c|c|c|c|c|}
\hline & & & NE & $\mathbf{R P}$ \\
\hline 1. Gond & [gond] & for God & $/ g \mathrm{gd} /$ & $/ \mathrm{gnd} /$ \\
\hline 2. Stonle & [stonl] & for stole & /stol/ & /stəひl/ \\
\hline 3. Thsick & [tsi:k] & for thick & $/ \mathrm{tik} /$ & /Olk/ \\
\hline 4. Quinlly & [kuInle] & for quickly & /kuIkle/ & /kwIkli/ \\
\hline 5. Feen & [fi:n] & for fee & /fi:/ & /fi:/ \\
\hline 6. Entertmated & [entætmeted] & for terminated & /tæmIncted/ & /t3:mIneItId/ \\
\hline 7. Iresponded & [IrespDnded] & for responded & /resppnded/ & /rIsppndId/ \\
\hline 8. Fifuty & [fifuti] & for fifty & /fifti/ & /fIfItt/ \\
\hline 9. Responted & [resIpDnted/ & for responded & /respbnded/ & /rIsppndid/ \\
\hline 10. Aspeted & [æspeted] & for arrested & /ærested/ & /ərestId/ \\
\hline
\end{tabular}


The way constraints are ranked in cases involving deletion is considered first. 'Caendar' and 'milely' are used to illustrate.

Tableau 1: The emergence of / kæendæ/

Input /kælində/(calendar) $\rightarrow$ output/kæendæ/

\begin{tabular}{clll}
\hline /kælində/ & $*$ MAX & *IDENT (low) & FAITH C \\
\hline (i)kælındə & $* !$ & $* *$ & $*$ \\
(ii)kæendæ & & & $*$ \\
(iii)kælendæ & $* !$ & & \\
\hline
\end{tabular}

Tableau 2: The emergence of /mIlele/

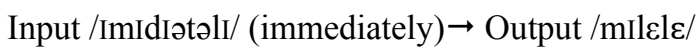

\begin{tabular}{|c|c|c|c|c|}
\hline /ImIdIətəli/ & *MAX & *IDENT (OBS) & *IDENT (central) & FAITH C \\
\hline (i)ImIdIətəlI & $* * !$ & $*$ & $*$ & \\
\hline (ii)ImIdIetəlI & $* * !$ & $*$ & $*$ & \\
\hline (iii)mIlele & & & & * \\
\hline
\end{tabular}

In Tableau 1, there are three output candidates for the input /kælIndə/: (i) represents the RP output; (ii) represents the aphasic's output; while (iii) represents the NE output. Both (i) and (iii) fatally violate *MAX which allows deletion of segments. (i) also violates *IDENT (low), which does not permit occurrence of low vowels in the output, twice; it contains $/ \mathrm{I} /$ and $/ \mathrm{o} /$. / kæendə/ emerges as the optimal candidate because it has the fewest lowest violations. In this candidate, /l/ (voiced alveolar lateral) has been deleted from the onset of the second syllable of the input. The peaks of the penultimate and the last syllables are different from that of the RP but they are similar to that of the NE. (ii) is able to emerge as the optimal candidate because the aphasic ranks the constraints thus: *MAX, *IDENT (low) >> FAITH C. This means that FAITH C is lowly ranked in the phonology of the aphasic; as such, its violation is not enough to prevent /kæendæ/ from emerging as the optimal output.

Tableau 2 shows the three output candidates for immediately: (i) RP output candidate fatally violates *MAX twice, by

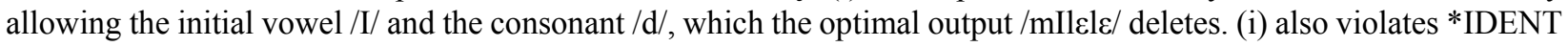
(OBS), a constraint that disallows the obstruent/t/ from appearing in the output; and *IDENT (central), a constraint that disallows the occurrence of the centring diphthong /Io/. Output candidate (ii) also fatally violates *MAX twice, the same way the RP candidate does. It violates IDENT (OBS), like candidate (i) does; its diphthong /I $\varepsilon$ / also violates *IDENT (back). However, the optimal candidate does not violate any of these constraints, because they are ranked as: *MAX, *IDENT (OBS) >> *IDENT (central).

Constraints ranking in cases involving substitution in the Wernicke's aphasics is considered next. Three words are used to achieve this end: 'Englit' and 'cawor'. Their output candidates are presented in Tableaux 3 and 4, respectively.

Tableau 3: The emergence of /IngIIt/

Input /Inglif/ (English) $\rightarrow$ Output/IngIIt/

\begin{tabular}{cccc}
\hline /Inglif/ & $*$ IDENT (manner) & *IDENT (place) & FAITH (coda) \\
\hline (i)Ingl/ & $* !$ & $*$ & \\
(ii)Inglif & $* !$ & $*$ & $*$ \\
(iii)Inglit & & & $*$ \\
\hline
\end{tabular}


Tableau 4: The emergence of /kæwD/

Input /kærət/ (carrot) $\rightarrow$ Output /kæwD/

\begin{tabular}{ccccc}
\hline /kærət/ & $*$ MAX & *IDENT(place) & IDENT(back) & FAITH C \\
\hline (i)kærət & $*$ & $* !$ & $*$ & \\
(ii)kærbt & $*$ & $* !$ & & $*$ \\
\hline
\end{tabular}

The case of the substitution in 'English' shown in Tableau 3 involves three constraints ranked as *IDENT (manner), *IDENT (place) $>>$ FAITH (coda). Though the RP output candidate (i) obeys FAITH (coda), it does not emerge as the optimal candidate. This is because *IDENT (manner), which disallows the output consonant from having identical manner of articulation with the input, and *IDENT (place) dominate FAITH (coda), which requires that coda in the output must be faithful to the coda in the input. Output candidate (ii) (NE output) fatally violates *IDENT (manner), just as (i) does; its last consonant has the same manner of articulation with the last consonant in the input /s/, which *IDENT (manner) disallows. Besides, it violates FAITH (coda), in that the coda of its first syllable is voiced alveolar nasal, instead of voiced velar nasal found in the input, in addition to violating *IDENT (place). Output (iii) emerges as the optimal candidate because it violates only FAITH (coda), which is ranked below *IDENT (manner). The way the constraints are ranked in the brain of the aphasic allows / $t$, which is voiceless alveolar plosive to replace the voiceless palato-alveolar fricative $/ \mathrm{J} /$.

There are two main phonological process involved in the case of 'kawor': substitution and deletion. The last consonant in the input (/t/, voiceless alveolar plosive) is deleted in the output candidate of the aphasic. $/ \mathrm{r} /$, which is in word-medial position in the input, is substituted as $/ \mathrm{w} /$ in the output candidate of the aphasic. /r/ is voiced post-alveolar approximant, while /w/ is voiced bilabial approximant. Both the RP and the NE output candidates ((i) and (ii), respectively) violate *MAX by not deleting /t/. Similarly, both also fatally violate *IDENT (place), as they permit a consonant that shares the same place of articulation with the input, which this constraint disallows. The RP output candidate also violates IDENT (back), as it does not have the back vowel /D/, which both the NE and the aphasic's output candidates have. The aphasic output candidate violates only FAITH C, which is a lowly ranked constraint. The aphasic's output candidate emerges as the optimal candidate because it has only one violation mark. In the language area of this aphasic, the constraints are ranked as *MAX, *IDENT (place) >> IDENT (back) FAITH C.

As it is with deletion, substitution in Wernicke's Aphasia involves ranking markedness above faithfulness (M $>>\mathrm{F})$. This ranking is responsible for the choices made by the patients in this study.

How constraints are ranked in cases of epenthesis is now considered. 'Resiponted' and 'Gond' are used to illustrate. Tableaux 5 and 6 capture this.

Tableau 5: The emergence of /resipDnted/

Input /rispDndId/ (responded) $\rightarrow$ Output /resipDnted/

\begin{tabular}{llll}
\hline /rIspDndId/ & $*$ DEP & *IDENT(low) & $*$ IDENT(voice) \\
\hline (i)resipDnted & & & $*$ \\
(ii)respDnded & $* !$ & & \\
(iii)rIspDndId & $* !$ & $*$ & \\
\hline
\end{tabular}

Tableau 6: The emergence of /gnnd/

Input /gDd / (God) $\rightarrow$ Output /gDnd/

\begin{tabular}{cll}
\hline$/ g D d$ & $*$ DEP & FAITH C \\
\hline (i) god & $* !$ & \\
$*$ (ii) gond & & $*$ \\
\hline
\end{tabular}

In Tableau 5, there is simplification of the consonant cluster/-sp-/ of the input in the optimal output. This is done through the epenthesis of $/ \mathrm{I} /$. The other two output candidates violate the constraint that allows this process, *DEP. This fatal violation disqualifies them from emerging as the optimal output. Besides, the RP output (iii) violates *IDENT (low), which disallows the appearance of the vowel /I/ in the output. The optimal output violates IDENT (voice), which requires that the voice of a consonant in the output should be identical with the voice of the same 
consonant in the input: /d/ is voiced alveolar plosive while/t/ (found in the optimal output) is voiceless alveolar plosive. The vowel in the last syllable of the optimal output is similar to that of the NE output, but different from that of the RP. In this case, the constraints are ranked as *DEP, *IDENT (low) $>>$ IDENT (voice).

There are two output candidates in Tableau 6, because the RP and the NE output candidates are similar. The second candidate /gDnd/ is the aphasic output candidate. Two constraints are involved in this derivation. The first output candidate fatally violates *DEP, because it has no epenthetic consonant. It, however, obeys FAITH C, because its consonants are faithful to the consonants in the input. The optimal candidate violates FAITH C. This violation is incapable of preventing it from emerging as the optimal candidate, because, in the language area of the aphasic, the constraints are ranked as *DEP $>>$ FAITH C.

Constraints ranking in the subjects shows that, owing to the damage to the brain, the language areas of the aphasics rank constraints in ways opposite to how non-aphasic adults do. The analysis also shows that FAITHFULNESS is lowly ranked, while MARKEDNESS is highly ranked in the language areas of bilingual Nigerian adult Wernicke's aphasics. This is why the ranking is always $\mathrm{M}>\mathrm{F}$.

\section{Conclusion}

The Wernicke's aphasics studied exhibited three principal forms of deviation: substitution, deletion and epenthesis. Deletion tops the list, followed by substitution. Consonants were more affected than vowels by these forms of deviation. Consonant deletion was more dominant in word-final position than the other two word positions. Vowel deletion affected the three word positions roughly equally. Substitution of consonants affected consonants in word-initial position more than those in the two other word positions. No case of vowel substitution was noticed in word-final position; vowel substitution was more common in word-initial position than word-final position. Consonant epenthesis featured more prominently in word-final position than the other two word positions. Vowel epenthesis occurred more frequently in word-medial and word-final position than word-initial position. The stricture associated with the production of consonants was largely responsible for their being affected by substitution and deletion more than vowels were.

Deletion of consonants affected plosives more than consonants with other manners of articulation. A reason for this is that plosives have the most extreme stricture. The place of articulation also exerted a great influence on deletion. Alveolar consonants were more affected by deletion than other consonants. This is because greater energy seems to be needed for the movement of the tongue to the alveola ridge. Bilabial plosives were nearly unaffected by deletion. This is because their articulation involves the two lips, which are almost always in contact during speech production. There was no consistent pattern of consonant substitution. Vowel substitution involved mainly /I/. This is a weak vowel often found in unstressed syllable. /I/ was often realized as $/ \varepsilon /$. Epenthesis of consonants involved $/ \mathrm{n} / \mathrm{mostly}$. $/ \mathrm{i} /$ was the mostly inserted vowel. Insertion of vowels was a strategy of simplifying consonant clusters. Vowel insertion resulted mainly because of the difficulty the subjects had with pronouncing syllabic consonants. Insertion of consonants was mainly due to the addition of $/ \mathrm{n} /$. This was common in subjects who had disfigured mouths through stroke.

The analysis of how constraints were ranked by the aphasics shows that the ranking is contrary to what obtains in non-aphasic adults. It also shows that the language area of these subjects ranks Markedness above Faithfulness (M $>>\mathrm{F})$. In their phonology, certain constraints are marked and seen as being more important than faithfulness.

In addition, the segments were not equally affected. Plosives and alveolars were more affected by deletion and substitution than any other class of consonants. This indicates that the brain is so specialized that different sections in it handle different classes of sounds. Otherwise, the sounds should have been equally affected.

\section{References}

Archangeli, D. (1997). Optimality Theory: An introduction to linguistics in the 1990s. Optimality Theory: an overview.D. Archangeli and Langendeon D.T. Eds. Oxford: Blackwell Publishers, 1-32.

Blumstein, S.E. (1973). A phonological investigation of aphasic speech. The Hague: Mouton.

Blumstein, S.E. (1988). Neurolinguistics: An overview of language-brain relations in aphasia. Linguistics: the Cambridge survey, vol.3: Language: psychological and biological aspects. F.J. Newmeyer. Ed. Cambridge: Cambridge University Press. 210-236.

Bouman, L., \& Grunbaum, A. (1925). Experimentell - Psychologische Untersuchungen zur Aphasie and Paraphasie. 
Zietschirift für gesanite Neurologie and Psychiatrie, 96, 481-538. http://dx.doi.org/10.1007/BF02896530

Caplan, D. (2003). Neurolinguistics. The handbook of linguistics, M. Aronff and J. Rose-Miller Eds. Oxford: Blackwell.582-607.

Caramazza, A., \& Zurif, E.B. (1976). Dissociation of algorithmic and heuristic processes in language comprehension: Evidence from aphasia. Brain and language, 3, 572-582. http://dx.doi.org/10.1016/0093-934X(76)90048-1

Cartell, R. (2006). An introduction to mind, consciousness and language. London and New York: Continuum.

Cho, S., \& Thompson, C.K. (2010). What goes wrong during passive sentence production in agrammatic aphasia: an eyetracking study. Aphasiology. iFIRST 1-17.

Choy, J.J., \& Thompson, C.K. (2010). Binding in agrammatic aphasia: processing to comprehension. Aphasiology, 24(5), 551-579. http://dx.doi.org/10.1080/02687030802634025

Congress on Child Language and Disorders. (2006). Call for papers. University of Port Harcourt, Port Harcourt.

Crystal, D. (1987). The Cambridge encyclopedia of language. Cambridge: Cambridge University Press.

Dickey, M.W., \& Thompson, C.K. (2004). The resolution and recovery of filler-gap dependencies in aphasia: evidence from on-line anomaly detection. Brain and Language, 88, 108-127. http://dx.doi.org/10.1016/S0093-934X(03)00283-9

Dickey, M.W., \& Thompson, C.K. (2009). Automatic processing of wh- and NP- movement in agrammatic aphasia: evidence from eyetracking. Neurolinguistics, 22, 563-583. http://dx.doi.org/10.1016/j.jneuroling.2009.06.004

Dickey, M. W., Choy J.J., \& Thompson, C.K. (2007). Real- time comprehension of wh-movement in aphasia: evidence from eyetracking while listening. Brain and Language, 100, 1-22. http://dx.doi.org/10.1016/j.bandl.2006.06.004

Edwards, S. (2002). Aphasia. The linguistics encyclopedia. K. Malmkjær. Ed. London and New York: Rougledge. 17-21.

Fox, A. (2002). Generative Phonology . The linguistics encyclopedia $\left(2^{\text {nd }}\right)$ Ed K. Malmakjær. Ed. London and New York: Routledge. 193-199.

Goldstein, K. (1948). Language and language disturbances. New York: Grune and Straton.

Goodglass, H., \& Kaplan, E. (1983). The assessment of aphasia and related disorders( $\left.2^{\text {nd }}\right)$. Ed. Philadelphia: Lea.

Goodglass, H., Gleason, J., Bernholtz, N.A., \& Hyde M.R. (1972). Some linguistic structures in the speech of a Broca's aphasic. Cortex, 8, 191-212.

Green, E. (1969). Higher cortical functions in man. New York: Basic Books.

Jakobson, R. (1968). Child language, aphasia and phonological universals. Trans. by A.R. Keiler. The Hague: Mouton.

Jakobson, R. (1971). Studies on child language and aphasia. The Hague: Mouton.

Kager, R. (1999). Optimality Theory. Cambridge: Cambridge University Press.

Lecours, A.R., \& Lhermitte, F. (1969). Phonemic paraphasias: Linguistic structures and tentative hypothesis. Cortex, 5, 193-228.

Luria, A.R. (1966). Higher cortical functions in man. New York: Basic Books.

McCarthy, J. (2002). A thematic guide to Optimality Theory. Cambridge: Cambridge University Press.

McCarthy, J., \& Prince, A. (1995). Faithfulness and reduplicative identity University of Massachusetts occasional papers in linguistics 18. J. Beckman, L.W. Dickey and S. Urbanczyk. Eds. Amherst, MA: GLSA. 249-384.

Moreton, E. (1996/1999). Non-computable functions in Optimality Theory. Unpublished Manuscript, Amherst: University of Massachusetts. (Written in 1996; revised and placed on Rutgers Optimality Archive in 1999).

Niemi, J. Koivuselka-Sallimen, P., \& Hanninen, R. (1985). Phoneme errors in Broca's aphasia: three Finnish cases. Brain Language, 26, 28-48. http://dx.doi.org/10.1016/0093-934X(85)90026-4

Oyeabade, F. (1998). A course in phonology. Ijebu-Ode: Shebiotimo Publications.

Parker, F. (1986). Linguistics for non-linguists. San Diego: College-Hill Press.

Peuser, G., \& Fittshen, M. (1977). On the universality of language dissolution: the case of a Turkish aphasic. Brain and Language, 4, 196-207. http://dx.doi.org/10.1016/0093-934X(77)90017-7 
Prince, A., \& Smolensky, P. (1993). Optimality Theory: constraints interaction in Generative Grammar. Report no. Ruccs-TR 2, Now Brunswick, NJ: Rutgers University Center for Cognitive Science.

Salami, O. (2005). Language disorder: an introduction. Perspectives on Language and Literature. M.Olateju and L.Oyeleye. Eds. Ile-Ife: Obafemi Awolowo University Press. 37-52.

Sunday, A.B. Phonological description of bilingual Nigerian adult aphasics. $\mathrm{PhD}$ thesis. University of Ibadan, Nigeria.

Sunday A.B. (2010) The suprasegmentals of bilingual Nigerian adult aphasics. SKASE Journal of Theoretical Linguistics, 7(2), 39-66.

Thompson C.K., \& Choy J.J. (2009). Pronominal resolution and gap filling in agrammatic aphasia: evidence from eye movement. J Psycholinguist Res. http://dx.doi.org/10.1007/s10936-009-9105-7

Thompson, C.K., \& Choy J.J. (2010). Sentactics ${ }^{\circledR}$ : computer automated treatment of underlying forms. Aphasiology, 24(10), 1242-1266. http://dx.doi.org/10.1080/02687030903474255

Thompson, C.K., \& Shapiro, L.P. (2005). Treating agrammatic aphasia within a linguistic framework: treatment of underlying forms. Aphasiology. 19(10/11), 1021-1036. http://dx.doi.org/10.1080/02687030544000227

Wertz, R.R. (1996). Clinical description. Adult Aphasta Rehabilitation, G.L. Wallace Ed. Boston and Oxford: Butterworth-Heinemann. 39-56.

Whitaker, H.A. (1975). Linguistics and neurology Linguistics and Neighbouring Disciplines, P. Bartschand T. Vennemann. Eds. Amsterdam: North-Holland Publishing Company. 33-42.

Wingfield A. (1992). Anomia. International encyclopedia of linguistics. Vol 1.W. Bright. Ed. New York and Oxford: Oxford University Press.64-65.

Zurif, E.B., Caramazza, A., \& Myerson, R. (1972). Grammatical judgements of agrammatic aphasics. Neuropsychologia, 10, 405-17. http://dx.doi.org/10.1016/0028-3932(72)90003-6 